\title{
Long-term management of chronic immune thrombocytopenic purpura in adults
}

\author{
This article was published in the following Dove Press journal: \\ International Journal of General Medicine \\ 2I September 2010 \\ Number of times this article has been viewed
}

\author{
Javier Palau \\ Isidro Jarque \\ Miguel A Sanz \\ Department of Hematology, Hospital \\ Universitario La Fe, Valencia, Spain
}

Correspondence: Javier Palau

Department of Hematology, Hospital

Universitario La Fe, Avenida Campanar,

21 46009 Valencia, Spain

Tel +34963862745

Fax +349619732 81

Email jarque_isi@gva.es

\begin{abstract}
Chronic immune thrombocytopenic purpura (ITP) is generally a more benign disease than previously thought. Currently it is recommended that only those patients with severe and/or symptomatic thrombocytopenia definitely require treatment. Additional factors, such as age, lifestyle, and uremia can also influence the hemorrhagic risk and should be carefully assessed before decision-making on the appropriate management of patients with less severe forms of ITP. The recent introduction of new classes of therapeutic agents such as rituximab and the thrombopoietic growth factors has had a major impact on the management of ITP. Updated treatment guidelines have recently been made available but they are based largely on expert opinion rather than on high-quality clinical trial evidence. This structured review is focused on the management of adults with chronic ITP, including the use of new classes of agents.
\end{abstract}

Keywords: corticosteroids, splenectomy, romiplostim, eltrombopag, rituximab

\section{Introduction}

According to the recent international consensus report, ${ }^{1}$ primary immune thrombocytopenia (ITP) is an acquired immune-mediated disorder characterized by isolated thrombocytopenia, defined as a platelet count $<100 \times 10^{9} / \mathrm{L}$, and the absence of any obvious initiating and/or underlying cause for thrombocytopenia. It can be classified by duration into newly diagnosed, persistent (3-12 month duration), and chronic ( $\geq 1$ year duration).

The pathogenic mechanism of thrombocytopenia in ITP was classically interpreted as increased platelet destruction mediated by autoantibodies. However, today it is well known that more complex mechanisms are involved including both impaired platelet production and T-cell-mediated effects..$^{2-6}$

The natural history of untreated ITP shows differences between adults and children. Typically, ITP in adults exhibits an insidious onset and normally follows a chronic course, ${ }^{7}$ whereas in children it is usually preceded by a viral infection and more than $60 \%$ of patients spontaneously achieve normal platelet counts within 6 months. A survey by the Intercontinental Childhood ITP Study Group (ICIS- 1$)^{8}$ involving more than 2,000 children showed a peak age of $1-5$ years, platelet counts at presentation $<20 \times 10^{9} / \mathrm{L}$, and slightly more in boys $(55 \%)$ than girls. Initial treatment of children with glucocorticoids, intravenous immune globulin (IVIG) or anti-D immunoglobulin (anti-D) may cause a more rapid increase of the platelet count compared with no therapy. ${ }^{9}$ However, it is not well established whether an early therapeutic intervention decreases morbidity from bleeding or increases complete remission rates. ${ }^{10}$ 
ITP during pregnancy have particular management needs closer to those of patients who develop acute thrombocytopenia and are outside the scope of the present review.

Spontaneous remissions occur rarely in adults. In general, adults with severe symptomatic thrombocytopenia are given treatment, most often with glucocorticoids. However, most patients do not maintain normal platelet counts after glucocorticoids are stopped. ${ }^{7-12}$

In general, ITP in adults is more prevalent in women (30-60 years). ${ }^{9,13}$ Signs and symptoms vary widely. Many patients have either no symptoms or minimal bruising, while others experience serious bleeding episodes that may include gastrointestinal (GI) bleeding, extensive skin and mucosal hemorrhage or intracranial hemorrhage (ICH). The severity of thrombocytopenia correlates to some extent with bleeding risk. ${ }^{13,14}$ Additional factors including age, lifestyle, and uremia can also influence the risk and should be carefully assessed before making a decision about the appropriate management. On the other hand, adults presenting with mild and asymptomatic thrombocytopenia, with platelet counts between $30 \times 10^{9} / \mathrm{L}$ and $50 \times 10^{9} / \mathrm{L}$, seem to have a stable and benign course without treatment..$^{7,13,15,16}$ Data from case series suggest that fewer than $20 \%$ of such patients eventually develop more severe thrombocytopenia and require treatment after 3-7 years of follow-up. ${ }^{7}$

Results from some long-term follow-up series suggest that ITP is a more benign disease than previously thought, and should be treated by a conservative approach, reserving aggressive treatment for patients with severe and symptomatic thrombocytopenia. ${ }^{7,13,16}$ The most relevant information from these series is: (i) most patients $(42 \%)$ have a platelet count $>50 \times 10^{9} / \mathrm{L}$ and remain untreated; (ii) the spontaneous remission rate is $9 \%$; and (iii) patients with a platelet count $<50 \times 10^{9} / \mathrm{L}$ had a good outcome, with only $12 \%$ presenting with frank bleeding, while $28 \%$ were asymptomatic, $19 \%$ did not need specific treatment, and $55 \%$ needed only first-line treatment.

Mortality attributable to thrombocytopenia is low ( $1 \%-4 \%)$, usually caused by severe bleeding and, more importantly, infections associated with immunosuppressive therapy. Splenectomy is associated with postoperative complications and may result in significant morbidity and costs derived from prolonged hospitalization or readmission in a sizable proportion of patients that has been reported up to $26 \%$. $^{16}$

In this article we will review the long-term management of chronic ITP in adults, including the role of rituximab and the new thrombopoietic growth factors.

\section{Treatment strategies \\ General therapeutic principles}

Because severe bleeding is rare in patients with ITP and normally occurs when platelet counts are $<10,000 / \mu \mathrm{L},{ }^{17}$ the main goal of therapy is to maintain a safe platelet count (not necessarily a normal count) to prevent major bleeding, while withholding drugs, when possible, to avoid adverse effects of therapy that often exceed any problems caused by the ITP. ${ }^{1}$ Keeping these criteria in mind, patients with mild, asymptomatic thrombocytopenia should not be treated unless they have a risky lifestyle (sports etc) ${ }^{18}$ or they are at risk for bleeding because of associated conditions (hypertension, cerebrovascular disease), ${ }^{15,19}$ have disorders requiring treatment with anticoagulant or antiplatelet agents, or a need for surgery or other invasive procedures. If patients have moderate or severe thrombocytopenia and bleeding symptoms, treatment must be started but should be limited in duration unless symptomatic thrombocytopenia persists.

The treatment decision-making in ITP should be shared between the clinician and the patient. As has been repeatedly emphasized, for some patients, the morbidity associated with side effects of therapy may exceed any problem caused by the ITP. Patients with life-threatening bleeding require immediate intervention. This situation is uncommon but more frequent in elderly patients $(10 \%-13 \%))^{7,15,19,20}$ Platelet transfusion is usually accepted as the initial therapy because it can provide critical temporary support, maintaining platelet counts above $20 \times 10^{9} / \mathrm{L}$ in a number of cases $(42 \%){ }^{21,22}$ Transfusions must be combined with IVIG $(1 \mathrm{~g} / \mathrm{kg}$, repeated the following day if the platelet count remains $\left.<50 \times 10^{9} / \mathrm{L}\right)$ and with intravenous pulse methylprednisolone ( $1 \mathrm{~g}$, repeated daily for 3 doses). If previous treatments fail, intravenous recombinant human factor VII can be successfully used. ${ }^{23-25}$

\section{First-line treatment}

Accurate initial diagnosis of ITP is necessary because some adults may have a self-limited thrombocytopenia caused by an infection or an adverse drug effect. ${ }^{13}$ Thus, treatment of concurrent infections or withdrawal of the implicated drug must be considered in the initial phases of ITP management. Among the acute and chronic bacterial and viral infections that have been associated with thrombocytopenia, the following microorganisms must be considered: hepatitis $\mathrm{C}$ virus, human immunodeficiency virus, cytomegalovirus, Epstein-Barr virus, parvovirus, and Helicobacter pylori ${ }^{26}$ In these cases, treatment of concomitant infection may improve the thrombocytopenia and steroids or immunosuppressive agents should be avoided because they may worsen the infection. ${ }^{27,28}$ 
Since spontaneous remissions are uncommon in adults with ITP, the administration of glucocorticoids is the recommended treatment when necessary. Prednisone ( $1 \mathrm{mg} / \mathrm{kg}$ per day orally) or high-dose dexamethasone (HDD), $40 \mathrm{mg} /$ day orally for 4 days, repeated every 14-28 days as needed, are the regimens most commonly used. However, only $20 \%$ of patients receiving prednisone as first-line treatment have a sustained complete remission lasting more than six months after maintenance therapy is discontinued. ${ }^{7}$ The role of HDD in first-line treatment of ITP in adults is well known. ${ }^{12,29,30}$ The best results with HDD are $85 \%$ initial response and, among responders, $50 \%$ will have a sustained response for up to 2 years. Advantages of this regimen are the short and defined duration of treatment compared with the more prolonged duration of daily oral prednisone treatment. ${ }^{31}$

\section{Second-line treatment and management of refractory ITP}

In case of glucocorticoid treatment failure (refractoriness or early relapse following withdrawal), a second-line treatment can be given when necessary. Treatment choice includes IVIG, anti-D in RhD-positive individuals (both can be used as a first option and classified as first-line treatment), splenectomy, and immunosuppressive drugs, including rituximab. Splenectomy remains the most effective option, with the highest rate of durable complete remissions, ${ }^{32}$ and provides long-lasting responses for the majority of cases. However, there are no randomized studies that give guidance on the most convenient order of using these distinct alternatives that will be discussed below.

\section{Splenectomy}

The decision to perform a splenectomy should take into account both the severity of bleeding and thrombocytopenia, as well as the risk of major bleeding. Splenectomy may not be appropriate for patients with mild or moderate thrombocytopenia and minor bleeding, except for patients with a lifestyle estimated to be at high risk for bleeding (police officers, firefighters, sports, high probability of accidents). The indication for splenectomy must be deferred until failure of first-line treatment for ITP is well documented and spontaneous recovery is judged to be unlikely. If necessary, splenectomy can be performed 4-6 weeks after diagnosis of treatment failure. ${ }^{1}$ If rituximab is used as a therapeutic alternative before splenectomy, the response should be evaluated after a minimum follow-up because responses can occur up to $6-8$ weeks later. ${ }^{60}$
The effectiveness of splenectomy is well known, and the main case series reported (not controlled studies, with heterogeneous patients and different follow-up) $)^{33,34}$ have comparable results: approximately two-thirds of patients recovered to a normal platelet count that persisted for the duration of observation. ${ }^{31,32,35}$ In 14 case series reporting only adults, $456(64 \%)$ of 707 patients had a complete response with a median follow-up of 7.25 years (range, $5-12.75$ years). ${ }^{32}$ There is a lack of reliable tools to accurately predict the response of ITP to splenectomy. In general, younger patients respond better,,$^{32,33,36,37}$ but a specific age cutoff for this observation has not been determined. Splenectomy is considered a low-risk surgical procedure, especially in previously healthy patients, but it must be performed by expert surgeons. Patients should be prepared to have a platelet count $>50 \times 10^{9} / \mathrm{L}$ before surgery, usually by giving a course of glucocorticoids, IVIG, anti-D, and/or platelet transfusions. Today, with the extent of laparoscopic techniques, the expected morbidity $(9.6 \%)$ and mortality $(0.2 \%)$ have dramatically decreased..$^{32,38-41}$

Because splenectomy may predispose to fatal infections by encapsulated bacteria (estimated mortality of 0.73 per 1,000 patient years), ${ }^{42}$ a consensus has been reached to recommend vaccination against Streptococcus pneumoniae (polyvalent vaccine), Hemophilus influenzae b, and Neisseria meningitides (conjugate vaccine). ${ }^{1}$ Vaccination must be done at least 4 weeks prior to splenectomy or alternatively 2 weeks after this surgical procedure.$^{81}$ It should be noted that vaccines may not be effective in patients treated with rituximab within the previous 6 months. ${ }^{81}$

Approximately $20 \%$ of patients relapse after splenectomy and exhibit severe ITP or have a risk of bleeding that requires additional therapy. In these refractory ITP patients, apart from reconsidering other potential causes of thrombocytopenia, the development of accessory spleens should be ruled out. The management of refractory ITP is a challenge and several therapeutic options can be considered. In addition, some refractory patients not meeting the criteria for severe ITP can face clinical situations with increased risk of bleeding, such as surgery, bucco-dental interventions or trauma in which there is a need for a rapid and temporary response. Corticosteroids, IVIG or thrombopoietic growth factors (see below) can be useful in these situations.

\section{Corticosteroids}

Both low-dose (prednisone 5-10 mg/day) and high-dose corticosteroids in brief courses have been used to maintain a safe platelet count in refractory patients. Experiences have 
been disappointing with failure to achieve complete remissions, short response times, and/or increased toxicity. ${ }^{43-46}$

\section{IVIG and anti-D}

Both agents increase the platelet count within several days in most patients with ITP, with an effect that may last for several weeks. ${ }^{10,36,47}$ However, neither modality is expected to induce a long-term remission. Nevertheless, these agents may be valuable in patients with life-threatening bleeding or prior to splenectomy or other surgical procedures.

\section{Immunosuppressive drugs and miscellaneous agents}

Several single agents have been used with marginal efficacy. Azathioprine, ${ }^{48}$ cyclosporin A, ${ }^{49,50}$ and cyclophosphamide ${ }^{51,52}$ are immunosuppressive drugs that have been used after treatment failure in both splenectomized and nonsplenectomized patients. Complete response rates vary from $24 \%$ to $85 \%$, but their use is limited because of the development of serious adverse effects such as infections, secondary tumors, hypertension or renal insufficiency. The list of drugs used in ITP also includes danazol, ${ }^{53}$ dapsone, ${ }^{54,55}$ or mycophenolate mofetil ${ }^{56,57}$ all with poorly defined efficacy. Interestingly, a recent retrospective, observational study reported encouraging results using a combination of azathioprine, mycophenolate mofetil, and cyclosporine in a relatively small series of patients with particularly severe and refractory ITP. ${ }^{58}$

\section{Rituximab}

This monoclonal antibody is being increasingly used off-label for refractory chronic ITP. Our main knowledge about efficacy and safety of this agent in this setting comes from a systematic review ${ }^{59}$ and a prospective multicenter phase II trial involving 60 patients treated with 4 weekly intravenous injections of rituximab $\left(375 \mathrm{mg} / \mathrm{m}^{2}\right.$ per dose $) .{ }^{60}$ Three important conclusions can be made: (i) rituximab achieved sustained platelet counts $\left(\geq 30 \times 10^{9} / \mathrm{L}\right)$ in $40 \%$ of patients; (ii) rituximab was discontinued because of side effects in only 1 patient; and (iii) in nonresponders, a good response was obtained in $60 \%$ of patients by splenectomy. Although the most used dose of rituximab in ITP patients is $375 \mathrm{mg} / \mathrm{m}^{2} /$ week for 4 weeks, the standard dose is not yet established. It seems that lower doses $\left(100 \mathrm{mg} / \mathrm{m}^{2} /\right.$ week for 4 weeks) could be useful to achieve responses and minimize adverse effects. High response rates have been also reported recently with rituximab combined with high dose dexamethasone. ${ }^{61}$ Although we must be cautious with these results, it seems that rituximab can be used without compromising the response to splenectomy in case of rituximab failure. ${ }^{60}$ Nevertheless, since some cases of progressive multifocal leukoencephalopathy have been reported after rituximab treatment in patients with lymphoproliferative or autoimmune disorders, additional long-term safety data are required before recommending the widespread use of this monoclonal antibody in refractory chronic ITP. ${ }^{62}$

\section{Antifibrinolytics}

In patients with severe bleeding in spite of other treatments and supportive measures, the use of antifibrinolytic agents such as oral or intravenous tranexamic acid or aminocaproic acid may be an appropriate adjunct measure. ${ }^{63}$

\section{Chemotherapy}

Vinca alkaloids as single agents, ${ }^{64,65}$ or several combinations of different doses of cyclophosphamide, prednisone, vincristine, etoposide, and azathioprine have been used in patients with refractory ITP and have achieved complete responses in $42 \%$ of patients. ${ }^{66-67}$

\section{Hematopoietic stem cell transplantation}

Although toxicities associated with stem cell transplantation are potentially fatal, both autologous and allogeneic transplantation have been used in refractory ITP patients. Remissions have been reported but very few have been durable. ${ }^{69-72}$ Clearly this approach must be reserved for patients with refractory ITP with severe bleeding complications unresponsive to other modalities.

\section{Other treatments}

Some miscellaneous treatments historically used are no longer justified because of their demonstrated lack of efficacy or excessive toxicity, including vitamin $\mathrm{C}$, colchicine, interferon, ex vivo perfusion of plasma using protein $\mathrm{A}$ immunoadsorption columns or plasmapheresis as an isolated approach.

\section{New thrombopoietic growth factors}

A better understanding of ITP pathogenesis has lead to the development of a novel nonimmunologic therapeutic approach by stimulating platelet production. Several types of thrombopoiesis-stimulating agents (eg, thrombopoietin (TPO) receptor agonists), including recombinant TPOs (which are no longer available), peptide TPO mimetics such as romiplostim, and nonpeptide TPO mimetics such as eltrombopag, have been developed in recent years. Both romiplostim and eltrombopag have been recently approved for clinical use in patients with chronic ITP refractory to corticosteroids, immunoglobulins, or splenectomy. 
Romiplostim consists of an $\operatorname{IgG}_{1}$ Fc component linked to a peptide domain with 4 binding sites for Mpl, the TPO receptor. ${ }^{71,72}$

With this structure, the development of antibodies to romiplostim or to endogenous TPO, as it was previously observed with the recombinant TPO polyethylene glycolconjugated human megakaryocyte growth and development factor (PEG-MGDF), is unlikely. Based on 2 Phase I/II trials, ${ }^{74,75}$ a parallel placebo-controlled Phase III trial, ${ }^{76}$ and an open-label study, ${ }^{77}$ the most important observations regarding the use of romiplostim are the following: (i) romiplostim produces a durable platelet response in both previously splenectomized (38\%) and nonsplenectomized patients (56\%); (ii) adult patients responding to romiplostim experience an improvement of health-related quality of life; ${ }^{78}$ (iii) side effects are very unusual, mild to moderate headache being the most frequent (39\%), although transient worsening of thrombocytopenia during the post-treatment period (vaginal hemorrhage) and deep venous thrombosis owing to secondary thrombocytosis have been occasionally reported; (iv) antibodies against endogenous TPO or romiplostim have not been reported.

Similarly, a Phase II dose-ranging trial ${ }^{79}$ and a randomized (2:1 drug to placebo), double-blind, placebo-controlled Phase III trial ${ }^{80}$ have provided the following information about the use of eltrombopag, which is a TPO nonpeptide mimetic: (i) toxicities and adverse effects of eltrombopag are low and similar to placebo, while patients receiving $50-75 \mathrm{mg}$ /day show a trend toward fewer bleeding events on therapy; (ii) eltrombopag achieves a platelet count $>50 \times 10^{9} / \mathrm{L}$ at 6 weeks in 59\% of splenectomized and nonsplenectomized patients, and platelet counts return to baseline within 2 weeks of the end of treatment; (iii) liver function test abnormalities are present in $13 \%$ of patients treated with eltrombopag.

Although most reported adverse effects with both thrombopoietic agents were mild, concerns have been raised over the increased bone marrow reticulin occasionally found in patients treated with romiplostim or eltrombopag. Because the clinical meaning of this observation is not well understood, subsequent long-term clinical trials will address the importance of this finding and whether routine monitoring is required.

Romiplostim is administered subcutaneously once weekly and the dose ranges from 1 to $10 \mu \mathrm{g} / \mathrm{kg}$, whereas eltrombopag is orally administered in doses ranging from 25 to $75 \mathrm{mg}$ daily. Dosages are chosen in order to achieve platelet counts $\geq 50 \times 10^{9} / \mathrm{L}$, considered the optimal threshold to reduce the risk for bleeding. Experience with these drugs is limited but, because of their mechanism of action, both are effective as long as they are maintained and they might be useful for temporary therapy when remission with other treatments is expected to be delayed or when a splenectomy is postponed.

\section{Algorithm for the management of ITP Conclusions and future research directions}

Although it was first described more than two centuries ago, progress in our understanding of the main aspects of ITP has only become significant in the last few years. However, the diagnosis of ITP continues to be one of exclusion, the first-line treatment (glucocorticoids) has been the same for more than 60 years, and the most effective second-line therapy continues to be splenectomy. Moreover, very limited knowledge has been obtained from the few randomized and controlled clinical trials conducted.

Nevertheless, some advances that have been relevant in recent years and that could change the paradigm of ITP management are:

- The introduction of rituximab as second-line treatment (before performing splenectomy), which is an interesting option to avoid or postpone splenectomy in patients with increased surgical risk.

- The new understanding that the pathophysiology of ITP is based not only on the destruction of platelets but on their impaired production in the bone marrow, which gives impetus to the use of the thrombopoiesis-stimulating agents romiplostim or eltrombopag. These agents have demonstrated their efficacy in controlling disease in both splenectomized and nonsplenectomized patients, with few adverse effects.

Finally, as the investigation of ITP has for years been mainly based on noncontrolled studies, recent efforts to achieve an international consensus on terminology, investigation, and management of patients with ITP is to be considered as an attempt to overcome the difficulties of the past and encourage future research focused on randomized trials and large multicenter prospective cohort studies. ${ }^{79}$

\section{Disclosure}

The authors report no conflicts of interest in this work.

\section{References}

1. Rodeghiero F, Stasi R, Gernsheimer T, et al. Standardization of terminology, definitions and outcome criteria in immune thrombocytopenic purpura of adults and children: report from an international working group. Blood. 2009;113:2386-2393.

2. Olsson B, Andersson PO, Jernas M, et al. T-cell-mediated cytotoxicity toward platelets in chronic idiopathic thrombocytopenic purpura. Nat Med. 2003;9:1123-1124. 
3. Chang M, Nakagawa PA, Williams SA, et al. Immune thrombocytopenic purpura (ITP) plasma and purified ITP monoclonal autoantibodies inhibit megakaryocytopoiesis in vitro. Blood. 2003;102:887-895.

4. McMillan R, Wang L, Tomer A, Nichol J, Pistillo J. Suppression of in vitro megakaryocyte production by antiplatelet autoantibodies from adult patients with chronic ITP. Blood. 2004;103:1364-1369.

5. Houwerzijl EJ, Blom NR, van der Want JJ, et al. Ultrastructural study shows morphologic features of apoptosis and para-apoptosis in megakaryocytes from patients with idiopathic thrombocytopenic purpura. Blood. 2004;103:500-506.

6. Zhang F, Chu X, Wang L, et al. Cell-mediated lysis of autologous platelets in chronic idiopathic thrombocytopenic purpura. Eur $J$ Haematol. 2006;76:427-431.

7. Stasi R, Stipa E, Masi M, et al. Long-term observation of 208 adults with chronic idiopathic thrombocytopenic purpura. Am J Med. 1995;98:436-442.

8. Kuhne T, Imbach P, Bolton-Maggs PH, et al. Newly diagnosed idiopathic thrombocytopenic purpura in childhood: an observational study. Lancet. 2001;358:2122-2125.

9. Segal JB, Powe NR. Prevalence of immune thrombocytopenia: analyses of administrative data. J Thromb Haemost. 2006;4:2377-2383.

10. Blanchette VS, Luke B, Andrew M, et al. A prospective, randomized trial of high-dose intravenous immune globulin $\mathrm{G}$ therapy, oral prednisone therapy, and no therapy in childhood acute immune thrombocytopenic purpura. J Pediatr. 1993;123:989-995.

11. Lilleyman JS. Management of childhood idiopathic thrombocytopenic purpura. Br J Haematol. 1999;105:871-875.

12. Cheng Y, Wong RS, Soo YO, et al. Initial treatment of immune thrombocytopenic purpura with high-dose dexamethasone. $N$ Eng $J$ Med. 2003;349:831-836.

13. Neylon AJ, Saunders PW, Howard MR, Proctor SJ, Taylor PR. Clinically significant newly presenting autoimmune thrombocytopenic purpura in adults: a prospective study of a population-based cohort of 245 patients. Br J Haematol. 2003;122:966-974.

14. Stasi R, Evangelista ML, Stipa E, et al. Idiopathic thrombocytopenic purpura: current concepts in pathophysiology and management. Thromb Haemost. 2008;99:4-13.

15. Cortelazzo S, Finazzi G, Buelli M, et al. High-risk of severe bleeding in aged patients with chronic idiopathic thrombocytopenic purpura. Blood. 1991;77:31-33.

16. Portielje JE, Westendorp RG, Kluin-Nelemans HC, Brand A. Morbidity and mortality in adults with idiopathic thrombocytopenic purpura. Blood. 2001;97:2549-2554.

17. Lacey JV, Penner JA. Management of idiopathic thrombocytopenic purpura in the adult. Semin Thromb Hemost. 1977;3:160-174.

18. Cines DB, Bussel JB. How I treat idiopathic thrombocytopenic purpura (ITP). Blood. 2005; 106:2244-2251.

19. Guthrie TH, Brannan DP, Prisant LM. Idiopathic thrombocytopenic purpura in the older adult patient. Am J Med Sci. 1988;296:17-21.

20. Carr JM, Kruskall MS, Kaye JA, et al. Efficacy of platelet transfusions in immune thrombocytopenia. Am J Med. 1986;80:1051-1054.

21. Baumann MA, Menitove JE, Aster RH, Anderson T. Urgent treatment of idiopathic thrombocytopenic purpura with single-dose gamma globulin infusion followed by platelet transfusion. Ann Intern Med. 1986;104:808-809.

22. Spahr JE, Rodgers GM. Treatment of immune-mediated thrombocytopenia purpura with concurrent intravenous immunoglobulin and platelet transfusion: a retrospective review of 40 patients. Am J Hematol. 2008; $83: 122-125$.

23. Gerotziafas GT, Zervas C, Gavrielidis G, et al. Effective hemostasis with $\mathrm{rFVIIa}$ treatment in two patients with severe thrombocytopenia and life-threatening hemorrhage. Am J Hematol. 2002;69:219-222.

24. Culic S. Recombinant factor VIIa for refractive hemorrhage in autoimmune idiopathic thrombocytopenic purpura. $\mathrm{Br} J$ Haematol. 2003;120:909-910.
25. Waddington DP, McAuley FT, Hanley JP, Summerfield GP. The use of recombinant factor VIIa in a Jehovah's witness with autoimmune thrombocytopenia and post-splenectomy hemorrhage. Br J Haematol. 2002;119:286-288.

26. Cines DB, Liebman H, Stasi R. Pathobiology of secondary immune thrombocytopenia. Semin Hematol. 2009;46(1 Suppl 2):S2-S14.

27. Stasi R. Therapeutic strategies for hepatitis and other infection-related immune thrombocytopenias. Semin Hematol. 2009;46(1 Suppl 2): S15-S25.

28. DiMaggio D, Anderson A, Bussel JB. Cytomegalovirus can make immune thrombocytopenic purpura refractory. Br J Haematol. 2009; 146:104-112.

29. Borst F, Keuning JJ, van Hulsteijn H, Sinnige H, Vreugdenhil G. Highdose dexamethasone as a first- and second-line treatment of idiopathic thrombocytopenic purpura in adults. Ann Hematol. 2004; 83:764-768.

30. Mazzucconi MG, Fazi P, Bernasconi S, et al. Therapy with high-dose dexamethasone (HD-DXM) in previously untreated patients affected by idiopathic thrombocytopenic purpura. A GIMEMA experience. Blood. 2007;109:1401-1407.

31. George JN, Vesely SK. Immune thrombocytopenic purpura let the treatment fit the patient. $N$ Engl J Med. 2003;349:903-905.

32. Kojouri K, Vesely SK, Terrell DR, George JN. Splenectomy for adult patients with idiopathic thrombocytopenic purpura: a systematic review to assess long-term platelet count responses, prediction of response, and surgical complications. Blood. 2004;104:2623-2634.

33. Fabris F, Tassan T, Ramon R, et al. Age as the major predictive factor of long-term response to splenectomy in immune thrombocytopenic purpura. Br J Haematol. 2001;112:637-640.

34. McMillan R, Durette C. Long-term outcomes in adults with chronic ITP after splenectomy failure. Blood. 2004;104:956-960.

35. Kumar S, Diehn FE, Gertz MA, Tefferi A. Splenectomy for immune thrombocytopenic purpura: long-term results and treatment of postsplenectomy relapses. Ann Hematol. 2002;81:312-319.

36. George JN, Woolf SH, Raskob GE, et al. Idiopathic thrombocytopenic purpura: a practice guideline developed by explicit methods for the American Society of Hematology. Blood. 1996;88:3-40.

37. Fenaux P, Caulier MT, Hirschauer MC, Beuscart R, Goudemand J, Bauters F. Reevaluation of the prognostic factors for splenectomy in chronic idiopathic thrombocytopenic purpura (ITP): a report on 181 cases. Eur J Haematol. 1989;42:259-264.

38. Katkhouda N, Mavor E. Laparoscopic splenectomy. Surg Clin North Am. 2000;80:1285-1297.

39. Tanoue K, Okita K, Akahoshi T, et al. Laparoscopic splenectomy for hematologic diseases. Surgery. 2002;131 Suppl 1:S318-S323.

40. Wu JM, Lai IR, Yuan RH, Yu SC. Laparoscopic splenectomy for idiopathic thrombocytopenic purpura. Am J Surg. 2004;187:720-723.

41. Dolan JP, Sheppard BC, DeLoughery TG. Splenectomy for immune thrombocytopenic purpura: surgery for the 21 st century. Am J Hematol. 2008;83:93-96.

42. Schilling RF. Estimating the risk for sepsis after splenectomy in hereditary spherocytosis. Ann Intern Med. 1995;122:187-188.

43. Stasi R, Brunetti M, Pagano A, Stipa E, Masi M, Amadori S. Pulsed intravenous high-dose dexamethasone in adults with chronic idiopathic thrombocytopenic purpura. Blood Cells Mol Dis. 2000;26:582-586.

44. Vesely SK, Perdue JJ, Rizvi MA, Terrell DR, George JN. Management of adult patients with persistent idiopathic thrombocytopenic purpura following splenectomy: a systematic review. Ann Intern Med. 2004; 10:112-120.

45. Borst F, Keuning JJ, van Hulsteijn H, Sinnige H, Vreugdenhil G. High-dose dexamethasone as a first- and second-line treatment of idiopathic thrombocytopenic purpura in adults. Ann Hematol. 2004;83:764-768.

46. van Staa TP, Leufkens HG, Cooper C. The epidemiology of corticosteroid-induced osteoporosis: a meta-analysis. Osteoporos Int. 2002;13:777-787. 
47. Scaradavou A, Woo B, Woloski BM, et al. Intravenous anti-D treatment of immune thrombocytopenic purpura: experience in 272 patients. Blood. 1997;89:2689-2700.

48. Quiquandon I, Fenaux P, Caulier MT, et al. Re-evaluation of the role of azathioprine in the treatment of adult chronic idiopathic thrombocytopenic purpura: a report on 53 cases. Br J Haematol. 1990;74:223-228.

49. Emilia G, Morselli M, Luppi M, et al. Long-term salvage therapy with cyclosporin A in refractory idiopathic thrombocytopenic purpura. Blood. 2002;99:1482-1485.

50. Kappers-Klunne MC, van't Veer MB. Cyclosporin A for the treatment of patients with chronic idiopathic thrombocytopenic purpura refractory to corticosteroids or splenectomy. Br J Haematol. 2001;114:121-125.

51. Verlin M, Laros RK Jr, Penner JA. Treatment of refractory thrombocytopenic purpura with cyclophosphamide. Am J Hematol. 1976;1: 97-104.

52. Reiner A, Gernsheimer T, Slichter SJ. Pulse cyclophosphamide therapy for refractory autoimmune thrombocytopenic purpura. Blood. 1995; $85: 351-358$.

53. Maloisel F, Andres E, Zimmer J, et al. Danazol therapy in patients with chronic idiopathic thrombocytopenic purpura: long-term results. Am J Med. 2004;116:590-594.

54. Vancine-Califani SM, De Paula EV, Ozelo MC, et al. Efficacy and safety of dapsone as a second-line treatment in non-splenectomized adults with immune thrombocytopenic purpura. Platelets. 2008;19:489-495.

55. Hernandez F, Linares M, Colomina P, et al. Dapsone for refractory chronic idiopathic thrombocytopenic purpura. Br J Haematol. 1995; 90:473-475.

56. Provan D, Moss AJ, Newland AC, Bussel JB. Efficacy of mycophenolate mofetil as single-agent therapy for refractory immune thrombocytopenic purpura. Am J Hematol. 2006;81:19-25.

57. Kotb R, Pinganaud C, Trichet C, et al. Efficacy of mycophenolate mofetil in adult refractory auto-immune cytopenias: a single center preliminary study. Eur J Haematol. 2005;75:60-64.

58. Arnold DM, Nazi I, Santos A, et al. Combination immunosuppressant therapy for patients with chronic refractory immune thrombocytopenic purpura. Blood. 2010;115:29-31.

59. Arnold DM, Dentali F, Crowther MA, et al. Systematic review: efficacy and safety of rituximab for adults with idiopathic thrombocytopenic purpura. Ann Intern Med. 2007;146(1):25-33

60. Godeau B, Porcher R, Fain O, Lefrere F, Fenaux P, Cheze S. Rituximab efficacy and safety in adult splenectomy candidates with chronic immune thrombocytopenic purpura: results of a prospective multicenter phase 2 study. Blood. 2008;112:999-1004.

61. Zaja F, Baccarani M, Mazza P, et al. Dexamethasone plus rituximab yields higher sustained response rates than dexamethasone monotherapy in adults with primary immune thrombocytopenia. Blood. 2010; 115(14):2755-2762.

62. Carson KR, Evens AM, Richey AE, et al. Progressive multifocal leukoencephalopathy after rituximab therapy in HIV-negative patients: a report of 57 cases from the Research on Adverse Drug Events and Reports project. Blood. 2009;113:4834-4840.

63. Kalmadi S, Tiu R, Lowe C, Jin T, Kalaycio M. Epsilon aminocaproic acid reduces transfusion requirements in patients with thrombocytopenic hemorrhage. Cancer. 2006;107:136-140.

64. Berchtold P, McMillan R. Therapy of chronic idiopathic thrombocytopenic purpura in adults. Blood. 1989;74:2309-2317.
65. Szczepanik AB, Sikorska A, Slomkowski M, Konopka L. The use of vinca alkaloids in preparation for splenectomy of corticosteroid refractory chronic immune thrombocytopenic purpura patients. Int $J$ Lab Hematol. 2007;29:347-351.

66. Boruchov DM, Gururangan S, Driscoll MC, Bussel JB. Multiagent induction and maintenance therapy for patients with refractory immune thrombocytopenic purpura (ITP). Blood. 2007;110:3526-3531.

67. Figueroa M, Gehlsen J, Hammond D, et al. Combination chemotherapy in refractory immune thrombocytopenic purpura. N Engl J Med. 1993; 328:1226-1229.

68. McMillan R. Long-term outcomes after treatment for refractory immune thrombocytopenic purpura. N Engl J Med. 2001;344:1402-1403.

69. Zaydan MA, Turner C, Miller AM. Resolution of chronic idiopathic thrombocytopenia purpura following syngeneic peripheral blood progenitor transplant. Bone Marrow Transplant. 2002;29:87-89.

70. Butler JP, Durrant ST, Frost T. Successful remission of chronic, refractory autoimmune thrombocytopenic purpura following non-myeloablative allogeneic stem cell transplantation. Bone Marrow Transplant. 2003;31:621-622.

71. Huhn RD, Fogarty PF, Nakamura R. High-dose cyclophosphamide with autologous lymphocyte-depleted peripheral blood stem cell (PBSC) support for treatment of refractory chronic autoimmune thrombocytopenia. Blood. 2003;101:71-77.

72. Passweg JR, Rabusin M. Hematopoietic stem cell transplantation for immune thrombocytopenia and other refractory autoimmune cytopenias. Autoimmunity. 2008;41:660-665.

73. Broudy VC, Lin NL. AMG531 stimulates megakaryopoiesis in vitro by binding to Mpl. Cytokine. 2004;25:52-60.

74. Newland A, Caulier MT, Kappers-Klunne M, et al. An open-label, unit dose-finding study of AMG 531, a novel thrombopoiesis-stimulating peptibody, in patients with immune thrombocytopenic purpura. $\mathrm{Br} J$ Haematol. 2006;135:547-553.

75. Bussel JB, Kuter DJ, George JN, et al. AMG 531, a thrombopoiesisstimulating protein, for chronic ITP. $N$ Engl J Med. 2006;355 $1672-1681$.

76. Kuter DJ, Bussel JB, Lyons RM, et al. Efficacy of romiplostim in patients with chronic immune thrombocytopenic purpura: a doubleblind randomised controlled trial. Lancet. 2008;371:395-403.

77. Bussel JB, Kuter DJ, Pullarkat V, Lyons RM, Guo M, Nichol JL. Safety and efficacy of long-term treatment with romiplostim in thrombocytopenic patients with chronic ITP. Blood. 2009;113:2161-2171.

78. George JN, Mathias SD, Go RS, et al. Improved quality of life for romiplostim-treated patients with chronic immune thrombocytopenic purpura: results from two randomized, placebo-controlled trials. $\mathrm{Br} J$ Haematol. 2009;144:409-415.

79. Bussel JB, Cheng G, Saleh MN, et al. Eltrombopag for the treatment of chronic idiopathic thrombocytopenic purpura. $N$ Engl J Med. 2007;357:2237-2247.

80. Bussel JB, Provan D, Shamsi T, et al. Effect of eltrombopag on platelet counts and bleeding during treatment of chronic idiopathic thrombocytopenic purpura: a randomised, double-blind, placebo-controlled trial. Lancet. 2009;373:641-648.

81. Provan D, Stasi R, Newland AC, et al. International consensus report on the investigation and management of primary immune thrombocytopenia. Blood. 2010;115:168-186.
International Journal of General Medicine

\section{Publish your work in this journal}

The International Journal of General Medicine is an international, peer-reviewed open-access journal that focuses on general and internal medicine, pathogenesis, epidemiology, diagnosis, monitoring and treatment protocols. The journal is characterized by the rapid reporting of reviews, original research and clinical studies across all disease areas.

\section{Dovepress}

A key focus is the elucidation of disease processes and management protocols resulting in improved outcomes for the patient.The manuscript management system is completely online and includes a very quick and fair peer-review system. Visit http://www.dovepress.com/ testimonials.php to read real quotes from published authors. 